2017 Global Fashion Management Conference at Vienna Proceedings: 531-535 (July 2017) https://doi.org/10.15444/GFMC2017.06.07.01

\title{
THE BACKGROUND MUSIC AT ART GALLERIES EXPERIENCE IN LISBON
}

\author{
Sandra Maria Correia Loureiro, Instituto Universitário de Lisboa (ISCTE-IUL) and \\ Business Research Unit (BRU/UNIDE), Portugal ${ }^{1)}$
}

Filipa Lima, Instituto Universitário de Lisboa (ISCTE-IUL), Portugal ${ }^{2)}$

\begin{abstract}
This study was conducted in real art galleries in Lisbon to explore whether the experience lived at an art gallery with or without music background may positively influence behavioral intentions directly or through the positive emotions and the memory created. A total of two hundred and eighteen questionnaire were collected from the seven art gallery. Findings reveal that the intentions to recommend and encourage others to visit the art gallery is a function of pleasant arousal and memories. In this study we also show the influence of background music in helping encoding the information provided by stimuli, which induce visitors to incentive others to visit the art gallery.
\end{abstract}

Keywords: art experience consumption, emotions, memory, background music

\section{INTRODUCTION}

The consumer experience at an art gallery has unique characteristics and so it is not possible to comparable with retailing industry (Joy \& Sherry, 2003; Uusitalo et al., 2012). In art exhibitions, consumer experience is strongly marked by the aesthetic stimulus perceived beyond the mere rational appraisal (Bourgeon-Renault, 2000; Cirrincione et al., 2014). Some go to art galleries thinking that is fashionable and well regarded by peers. Others are involved with the exposed art and artists. However, all may can internalize incoming stimuli, which can give pleasure/displeasure and create memories.

Music presence affects the individuals' emotional states and this, in turn, influences their perceptions of art (Jain \& Bagdare, 2011). Yet, the way the presence or the absence of music affects the relationship between pleasure and behavioral intentions and between memory and behavioral intention is not completely established. Therefore, the current study explore whether the experience lived at an art gallery with or without music background may positively influence behavioral intentions directly or through the positive emotions and the memory created.

\section{THEORETICAL BACKGROUND}

Experiences are connected to emotions (Holbrook \& Hirschman, 1982; Joy \& Sherry, 2003; Silvia, 2005; Bourgeon-Renault, Urbain, Petr, Le Gall-Elly, \& Gombault, 2006) and cognitive stimulation in order to encode memories (Oh, Fiore, \& Jeoung, 2007).

\footnotetext{
1) sandramlouriro@netcabo.pt

2) filipalima_21@ @otmail.com
} 
Emotions are the consequence of a cognitive process of appraisal (Roseman \& Evdokas, 2004) that can come from the stimuli of paintings in an art gallery. Pleasant ambient enhances memory of products when mediated by attention (Dolcos \& Cabeza, 2002; Morrin \& Ratneshwar, 2000, 2003) and increase the likelihood to revisit and recommend the store or the place (Baker et al., 2002; Otto \& Ritchie, 1996). When visitor engage in a pleasant art exhibition experience they may focus their attention to the paintings and enhance their memory formation about the paintings. The stimuli get from art exhibition experience will lead in the visitors mind an intention to revisit and recommend to others.

Therefore: H1: The art gallery experience positively influence visitors' pleasant arousal: H2: The art gallery experience positively influence visitors' behavioral intention: H3: The art gallery experience positively influence visitors' positive memories; H4: Visitors' pleasant arousal positively influences their positive memories.

Based on S-O-R framework emotions should act as mediators between stimuli and outcomes and so, behavioral intentions can be enhanced by emotions (Baker et al., 2002). A positive memory also increases the likelihood of repeating visits and positive word-of-mouth communications (e.g., Dolcos \& Cabeza, 2002; Loureiro, 2014). Therefore, a visitor of an art gallery who have a favorable experience will be more likely to recommend to others and such behavior will be enhanced by pleasuring emotions and memory creation. Hence, pleasant arousal may act as mediator between art gallery experience and memory formation, as well as behavioral intention to recommend to others.

Thus, H5: Visitors' pleasant arousal positively influences visitors' behavioral intention; H6: Visitors' memory positively influences visitors' behavioral intention.

Considering previous studies on background music, highlighting that background music and visual stimulus can compete in the consumers' mind and induce unfavorable artwork (paintings) evaluation (e.g., Cauberghe \& De Pelsmacker 2010; Eskine et al., 2012; Choi, Lee, \& Li, 2014). However, music can also help cognitively to encode information about a brand or product in consumer's mind (Banbury et al., 2001; Choi et al., 2014). In this vein, it is expected that music may play a role in the cognitive process to appraisal art and in the behavioral intention to revisit the gallery and recommend to others. And so we propose: H7: Background music moderate the positive relationships between pleasant arousal and behavioral intention $(\mathrm{H} 7 \mathrm{a})$ and memory and behavioral intention (H7b).

\section{METHOD}

Seven art gallery located in Lisbon and well known in the market accepted to collaborate in the study. Four were assigned to the scenario without background music because we did not find any appropriate possibility to introduce a background music homogeneously. We did not change the other elements in the space of the gallery store in order to keep as usually. The galleries show artists with different styles in their artworks. Data collection occurred during a period of five mouths. During the period of time of the study the owners of the galleries keep the same exposition (even the paintings sold were not removed) and the same background 
music. A total of two hundred and eighteen questionnaires were collected from the seven art galleries, 114 from art galleries without background music and 104 from art galleries with background music. A pilot sample with ten visitors and owners of art galleries was used to ensure that the wording of the questionnaire was clear and only a few adjustments were made.

Art gallery experience was measured using 6 items adapted from Brakus et al. (2009). The study used three items to assess the construct memory, based on Pine and Gilmore (1999) and Oh et al. (2007). The four items measuring behavioral intentions were based on Zeithaml et al. (1996) and Loureiro and González (2008). All the items were rated using a 5-point Likert type scale (1 - strongly disagree to 5 - strongly agree).

\section{RESULTS}

They participated in the study individuals of both genders (62\%female) most are between 26 to 50 years old (45\%). The majority of participants are resident in Portugal (79\%). Most participants visit museums and galleries on average 2 in 2 months or 1 time per month. Participants also tend to spend less than 2 hours by week reading and visualizing art.

PLS was employed to estimate the measurement and structural parameters of the structural equation model. The adequacy of the measurements was assessed by evaluating the reliability of the individual measures and the discriminant validity of the constructs. Item reliability was assessed by examining the loading of the measures on their corresponding construct. Items with loadings of 0.707 or higher should be accepted, which indicates that over $50 \%$ of the variance in the observed variable is explained by the construct. All items have an item loading higher or equal to 0.707 . The reliability of the constructs was analyzed using composite reliability, since it has been considered a more accurate measurement than Cronbach's alpha. All constructs are reliable since the composite reliability values are over 0.8 (even intentions in the case of without music). The measures also demonstrated convergent validity as the average variance of manifest variables extracted by constructs is at least 0.5 . In our case, all constructs have discriminant validity because all correlations are lower than the square root of variances extracted. The two steps score construction procedure was employed to test the hypotheses. All path coefficients are found to be significant at the $0.001,0.01$ or 0.05 level, except for Experience $\rightarrow$ Intention in both cases with and without music and for Memory $\rightarrow$ Intention, but only for the case without music.

Finally, the differences between the samples of art galleries without music and with music background are compared using a parametric analysis through at test of $m+n+2$ degrees of freedom following the formula proposed by Chin (2004). The relationship between art gallery experience and pleasant arousal, as well as the relationship between memory and behavioral intentions are significantly higher in the case of art galleries with music than in art galleries without background music.

\section{CONCLUSIONS AND IMPLICATIONS}

Overall, the art gallery experience seems to be more effective in enhancing pleasant arousal than memory. Even so, background music may help visitors to memorize the art gallery and enhance the behavioural intentions. The findings are in accordance 
with previous research, which demonstrate the influence of experiences in developing emotions (e.g., Holbrook \& Hirschman, 1982; Silvia, 2005; Bourgeon-Renault, Urbain, Petr, Le Gall-Elly, \& Gombault, 2006) and memories (Dolcos \& Cabeza, 2002). The stimuli of paintings and its disposition in the art gallery together with pleasure of visualize the whole scenery contribute to create memories, particularly when having a background music which fit with the characteristics of the artwork.

The intentions to recommend and encourage others to visit the art gallery is a function of pleasant arousal and memories. Actually, pleasant arousal is a mediator between experience and behavioral intentions. In this vein, the positive emotions felt during the experience are the key to open new links in memory which, in turn, lead visitors to act as communicators of the art gallery. In this study we show the influence of background music in helping encoding the information (Banbury et al., 2001; Choi et al., 2014) provided by stimuli and induce visitors to incentive others to visit the art gallery.

The findings give some valuable insights to art gallery managers. A background music that fit the style of the art painting exposed at the art gallery. Music contribute significantly not only to generate positive emotions but above all to create memories. Those memories are important drivers to come again and by a painting, but also to call others to come to the art gallery. Therefore, it will be important that art gallery managers provide a background music, not too laud, but emblematic and in accordance to what paintings are representing. For instance, painting from Renaissance with music from the Renaissance or modern art and rock music.

\section{REFERENCES}

Bourgeon-Renault, D., Urbain, C., Petr, C., Le Gall-Elly, M., \& Gombault, A., (2006). An experiential approach to the consumption of value of arts and culture: The case of museums and monuments. International Journal of Arts Management, 9(1), 35-47. Retrieved from: https://www.gestiondesarts.com/en/anexperiential-approach-to-the-consumption-value-of-arts-and-culture-the-caseof-museums-and-monuments/\#.VgbcEhFViko

Brakus, J. J., Schmitt, B. H., \& Zarantonello, L. (2009). Brand experience: What is it? How is it measured? Does it affect loyalty? Journal of Marketing, 73(3), 52-68. doi: http://dx.doi.org/10.1509/jmkg.73.3.52

Dolcos, F., \& Cabeza, R. (2002). Event-related potentials of emotional memory: encodingpleasant, unpleasant, and neutral pictures. Cognitive, Affective, \& Behavioral Neuroscience, 2(3), 252-263. doi:10.3758/CABN.2.3.252

Holbrook, M. B., \& Hirschman, E. C. (1982). The experiential aspects of consumption: Consumer fantasies, feelings, and fun. Journal of Consumer Research, 9(2), 132-140. doi: 10.1086/208906

Loureiro, S.M.C. (2014). The role of the rural tourism experience economy in place attachment and behavioral intentions. International Journal of Hospitality Management, 40 (5 July), 1-9. doi: 10.1016/j.ijhm.2014.02.010

Loureiro, S. M. C., \& Miranda, F. J. (2008). The importance of quality, satisfaction, trust and image in relation to rural tourism loyalty. Journal of Travel \& Tourism Marketing, 25(2), 117-136. doi:10.1080/1054840080240232 
Oh, H., Fiore, A. M., Jeoung, M. (2007). Measuring experience economy concepts:tourism applications. Journal of Travel Research, 46(2), 119-132. doi:10.1177/0047287507304039

Pine, B. J. II, \& Gilmore, H. J. (1999). The experience economy: Work is theatre \& every business a stage. Boston, MA: Harvard Business School Press.

Zeithaml, V. A., Berry, L.L. \& Parasuraman, A. (1996). The behavioural consequences of service quality. Journal of Marketing Management, 60 (No. April), 31-46. doi:10.2307/1251929

\section{More references upon request}

